\title{
Qui sóc? D'on vinc? Cap on vaig? Una mirada a la vida
}

\author{
Xavier Inglès i Bo \\ Escola Joan Perucho d'Albinyana \\ xingles@xtec.cat
}

Resum: Treballar les arrels per llançar-se a la vida. Per mitjà de la construcció d’un lapbook explorem amb pinzellades qui som, amb el treball del nom per conèixer millor la nostra targeta de presentació; dissenyem un genograma i un fotograma per endinsar-nos en el nostre sistema familiar i descobrir d'on venim, i finalment modelem la nostra línia de la vida, cap on anem, per aixecar el vol cap al nostre futur. Tot amb la mirada amorosa cap a la nostra família. Al final fem un ritual amb les famílies per esculpir l'última part del treball $i$ tancar aquest curs del cicle (1r) i encaminar-nos cap al següent (2n).

Paraules clau: apoderar; fotograma; genograma; línia de vida; sistema; dimensió simbòlica; lapbook; ritual; vida; pedagogia sistèmica multidimensional.
Abstract: We must work on our roots to embark ourselves on life. Throught the carrying out of a "lapbook", we can explore brushstrokes about the "who I am?". Working with our names we ge.t a better understanding of our calling cards; we desing a genogram and a frame to get deep into our families system "where we com from?" At the end, we mould our life line, the "where I am going?", to start the flight towards our future. All of theses steps we have to do, we will do them in the loving sight of our family. Finally, we hold a ritual with families to define the end of this task and complete this grade (First 1st) and to guide ourselves to the next cycle (Second 2nd).

Keywords: seized; frame; genogram; life line; system; symbolic dimension; lapbook; ritual; life; systematic multidimensional teaching. 
En aquest article presento l'experiència duta a terme amb el grup classe del qual sóc tutor per donar-los ales per llançar-se a la vida i que de tot plegat en treguin ser més feliços, més coneixedors d'ells i d’elles mateixos, amb l'embolcall de la seva família.

\section{Objectius}

Lobjectiu principal de l'experiència ha sigut fer un treball d'apoderament amb els i les alumnes de la classe.

Aquest objectiu el vaig concretar en:

- Conèixer-nos a nosaltres mateixos, sota el lema “Qui sóc?". Fer un treball del nom i del fotograma.

- Conèixer, saber i apreciar el nostre sistema familiar, sota el lema "D’on venim?". Treballar el genograma acompanyant-lo d'un recull de fotografies de la gent més propera del propi sistema familiar.

- Llançar-nos a la vida, sota el lema "Cap on anem?", amb el treball de dibuixar la línia de la vida.

- Fer un ritual de tancament del treball i del curs per deixar les coses ben lligades $i$ aprofitar per obrir les noves portes al curs vinent.

\section{Contextualització}

El grup classe on he portat a terme l'experiència és un grup de primer de primària que ha triat com a nom de classe la malva, amb setze alumnes ( 8 nenes i 8 nens). Tots, menys dos alumnes que s'han incorporat aquest curs, han anat des de la llar d'infants junts, cosa que els fa ser un grup cohesionat. Els pares dels alumnes, excepte en un cas, viuen plegats i l'atur no ha fet gaires estralls en aquestes famílies.

Decidir fer aquest treball va ser degut a part del meu procés personal dins dels dos anys del màster. El treball que vaig fer del meu sistema familiar i d'apoderament cap a la vida em va arrelar molt profundament $\mathrm{i}$ ja des de l'inici d'aquest segon any del màster vaig pensar encaminar el treball de fi de curs cap aquests tres temes: qui sóc?, d’on vinc?, cap on vaig? Vaig incloure la fra- se "Una mirada a la vida" perquè és un treball de mirada de la vida de cadascú amb el coet final d'apoderament i de llançar-se cap aquesta per fruir-ne.

Cal dir que la col-laboració dels pares ha sigut absoluta i molt profitosa.

\section{Fonamentació}

Aquest treball s'ha fonamentat en les diverses teories tractades en els dos cursos del màster, com:

La teoria general de sistemes: un sistema és una xarxa interconnectada i, per tant, qualsevol canvi genera moviment en la resta (idea de circularitat). Sabent, doncs, que el canvi de mirada generarà moviments, ens hem de fixar en allò que podem fer i crear, així, en les possibilitats (Bertalanffy,1981).

La teoria de la complexitat: un sistema es basa en la diversitat, l'autoorganització i la cooperació. La realitat sempre és complexa i hi intervenen moltes variables i circumstàncies, difícilment simplificables. El millor enfocament pot ser prestar atenció i confiar que la situació que en un moment és disfuncional conté, en el seu interior, la solució que necessita (Morin, 2005).

El constructivisme: volem que la nostra tasca fomenti en els infants una bona autoestima, un sentiment de competència (molt relacionat amb la idea de l'infant capaç que ens aporta la neurobiologia) i de reconeixement per tal que se sentin a gust i feliços i puguin aprendre significativament, tal com apunta l'aprenentatge constructivista (Vygotski, 1979; Coll i Onrubia, 2001).

La teoria de la comunicació humana: un aprenentatge significatiu es basa en l'emoció, i això ens porta a parlar de l'educació com a essència comunicativa (Watzlanwick, 1995).

Les aportacions de Bert Hellinger: els ordres de l'amor de Hellinger (2001, 2012) són un pilar fonamental sobre el qual s'ha construit la pedagogia sistèmica: el dret a la vinculació/ pertinença, l'equilibri entre donar i rebre i la jerarquia.

La física quàntica: com diuen Traveset i Parellada, "s'enfonsen les certeses amb la física quàntica" (2014: 23). Aquí cal destacar un aspecte que està estretament lligat amb el que la física anomena camps mòrfics (o camps d’energia que 
estan regits per patrons d'interacció imperceptibles). Aquesta mirada suposa, doncs, substituir les teories estàndard que intenten enquadrar les actituds i les maneres de ser i de fer dels infants en teories universals per una mirada centrada en l'infant, en el que passa en el seu sistema.

La neurobiologia: en aquesta línia i partint de la idea de la neurobiologia que primer és l'espai i després la fecundació, una premissa que considerem fonamental és que l'aula ha de ser un lloc on es promoguin aquest tipus d'interaccions a través de les quals els infants puguin viure i experimentar una relació entre el que passa dins seu i el que passa fora, el que passa a l'escola i el que passa a casa, perquè aquesta coherència entre el món intern i el món extern té un paper fonamental en la nostra felicitat (Traveset i Parellada, 2014).

La neurociència: ens aporta tota una sèrie de noves informacions que ens ajudaran a canviar la mirada cap als nostres alumnes. El fet de tenir al grup nens i nenes neurotípics i neurodiversos fa que hàgim de tenir en compte moltes més coses de les que hem tingut en compte fins ara. Tenir alumnes neurodiversos, que cada cop seran més, ens ha de fer veure que la manera de treballar a la classe ha de canviar per agafar camins on els alumnes puguin treure tot el bagatge que ja porten a les seves motxilles i endinsar-se dins del món del coneixement $i$ el saber amb felicitat $i$ amb il.lusió (Damasio, 2004).

Les intel-ligències múltiples de Gardner: lligat amb l'apartat anterior, apareixen les intel-ligències múltiples de Gardner (2010). Aplicar el concepte de les intel-ligències múltiples promou estratègies didàctiques i metodològiques diferents. Partim del supòsit que el nen ja és intel-ligent, però ha d'escollir una manera de manifestar aquesta intel-ligència $\mathrm{i} \mathrm{amb}$ això haurà de crear productes de les seves intel-ligències: individuals, grupals i sostinguts per la comunitat de referència.

\section{Metodologia}

Com a dinàmiques d'aula he utilitzat:

El treball individual, en el qual cada alumne ha fet una recerca individual per demanar informació a la família, triar fotografies per al genograma, construir el seu propi treball i explicar-lo a la resta de la classe.

El treball de gran grup (alumnes), en el qual tots hem escoltat les explicacions del treball de cadascú i també hem fet intervencions amb preguntes, comentaris...

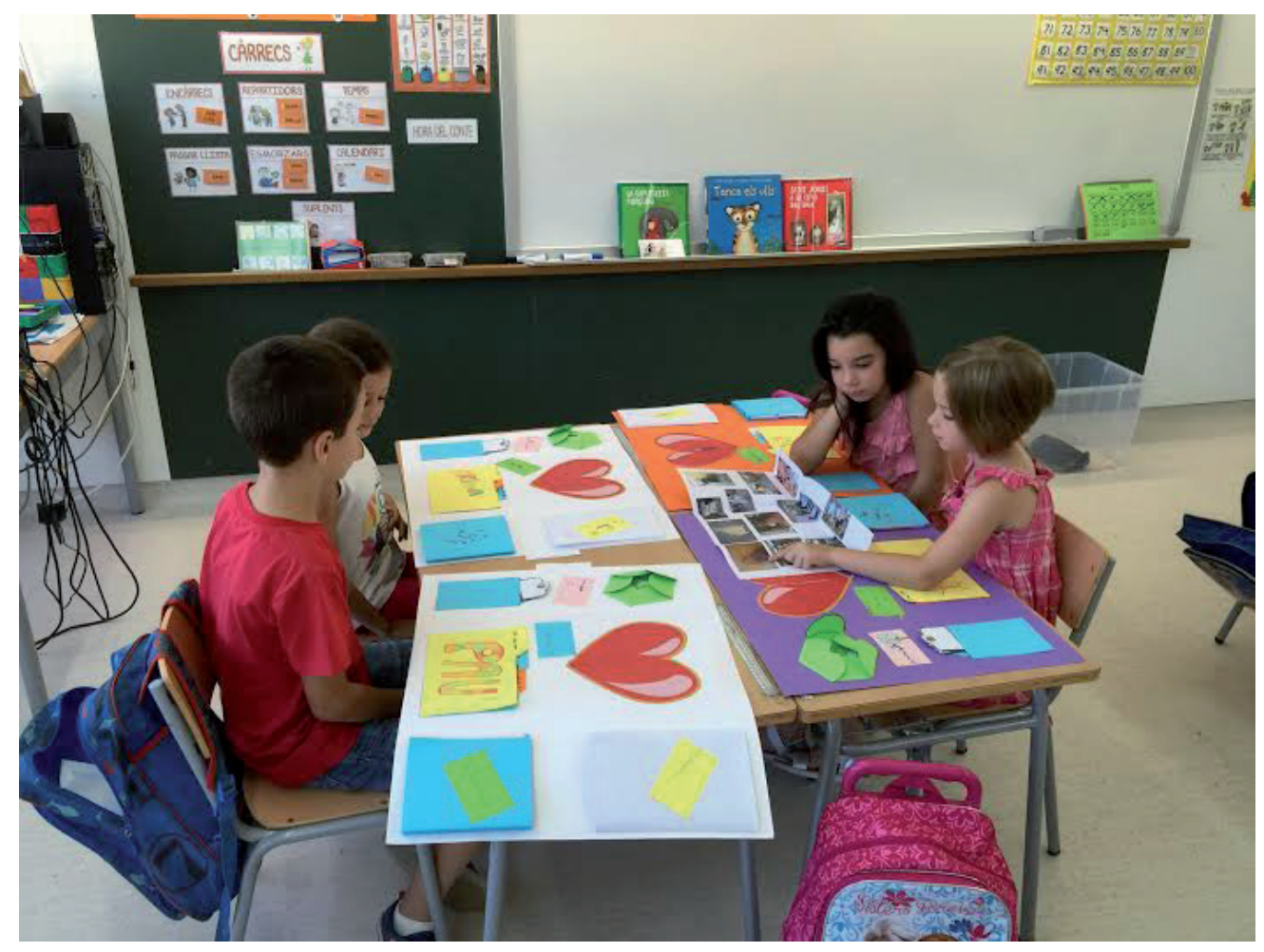


El treball en grups reduïts (famílies-alumnes). Per un costat, en el moment de recopilar la informació que s'havia de portar a classe per fer el treball $i$, per l'altre, en el ritual de tancament final i en el treball fet conjuntament per pares i fills per tancar el treball.

La intervenció de les famílies ha sigut del tot important pel fet de tractar temes que els toquen molt directament (nom, genograma i fotograma), $i$, alhora, molt interessant pel procés que han i hem fet durant tot el projecte, des de l'inici fins al final, amb el treball de tancament. En un primer moment, el fet d'haver de recopilar fotografies de la família els ha suposat una gran implicació, amb el trasbals que comporta, ja que molts no tenien gaires fotografies i han hagut de fer una recerca acurada per trobar-ne com més millor. Remarco la complicitat establerta i el respecte pel treball, ja que vam decidir a la classe que seria un secret fins al ritual de tancament. Aquest secret el desvelaríem a les famílies en el moment de fer la part final del treball.

\section{Procediment}

El treball plantejat va ser dissenyat per fer una part individual important de recerca d'informació amb les famílies: cada alumne va haver de demanar dades per construir el genograma i fotografies diverses.

La instrucció, des del primer moment, va ser que compartissin aquesta recerca i que tot el que aportessin a classe hagués sigut, amb anterioritat, consensuat entre els alumnes i els seus pares.

Després hi va haver una segona fase en la qual cada alumne explicava a la resta les diferents parts del seu treball:

- El perquè d'haver triat les fotografies que constaven al fotograma o al recull familiar.

- El seu genograma: qui eren els avis, com es deien, si encara els tenien o si algun ja havia mort...

- El seu nom: què volia dir, qui li havia posat, ensenyar i explicar-ne la representació gràfica.

- La composició del seu nucli familiar, tenint en compte que hi havia dos nens que eren nous i no coneixien del tot les famílies de la resta.

- La seva línia de vida.

En una tercera fase i de manera individual, de totes les fotografies que havien portat n'havien de seleccionar unes quantes que serien les que servirien per posar al fotograma.

Finalment, en una quarta fase, conjuntament amb les famílies, s'hauria de fer un treball final de construcció d'una portada i posar-hi un títol que aglutinés tot el contingut.

\section{Tècniques o eines utilitzades}

\section{El genograma}

Lobjectiu d'utilitzar aquesta eina és que permet recollir en un document informacions importants que han modelat durant anys i anys la família. Aquestes informacions ens poden ajudar a percebre fets i accions que ara, en l'actualitat, tinguin conseqüències en els membres d'aquesta família, i, si la influència del que va passar és desfavorable, a poder trobar imatges de solució per reconduir-les.

En el cas d'aquest treball amb nens i nenes de primer de primària, vam realitzar el genograma fins als avis. Això ens va ajudar a entendre que sense aquelles persones que havíem escrit en aquell full (avis i pares) nosaltres no hauríem existit. També, la mort d'alguns d'ells ens va permetre acceptar el fet de no tenir-los a prop i entendre que sempre els portem en el nostre cor.

En la preparació del treball, tot demanant la informació i comentant-la amb els alumnes, em vaig adonar que n'hi havia uns quants que no coneixien gaire els avis i fins i tot un d'ells els tenia a Amèrica del Sud. Aquest treball va servir per a conèixer-los i tenir-los presents una mica més.

\section{El fotograma}

Representa un àlbum de fotos de la família però amb la particularitat que no recollim totes les fotografies que tenim sinó que triem les que creiem que tenen les escenes més interessants de la nostra vida. Escollim les més importants del procés de la nostra vida vinculades a les persones que formen el nostre sistema. 
Vam construir dos fotogrames. Un com a recull de les fotografies de la vida, i un altre en què sortien els familiars més directes: avis, tiets, cosins germans...

\section{El nostre nom}

El nom com a eina d'identificació primera i de presentació envers els altres. El nom de cadascú, que té un origen; el nom que algú va pensar i ens va posar. Que té un significat i, per tant, per mitjà d'aquest significat porta un munt d'informacions que poden tenir certa importància en la nostra manera de ser en la vida i en la relació envers els altres: amics, familiars, etc.

\section{La dimensió simbòlica: la línia de vida}

Les imatges ens poden aportar molta informació del món de les relacions dins de la nostra família (dibuix de la família). En aquestes imatges podem observar com es troben aquestes relacions i això ens aporta molta informació per entendre l'actuació d'una persona, d'un alumne.

En el treball que tractem en l'apartat "Cap on anem?", els alumnes van dibuixar la seva línia de la vida des del naixement fins a la mort, posant els moments, per a ells, clau del recorregut de la seva vida.

\section{El lapbook}

Un lapbook és un suport desplegable en cartolina o cartró que permet exposar un tema. A l'interior és possible incorporar-hi diversos suports: esquemes, fotos, dibuixos, desplegables...

La seva principal utilitat és que permet treballar amb el nen tot un projecte concentrant-lo en una sola peça amb molta informació, d'una manera tan gràfica com senzilla i divertida.

El lapbook resulta molt útil a l'hora d'exposar el projecte davant dels companys i de les companyes a classe.

\section{Descripció del procés}

Quan em vaig posar a pensar com es podria dur a terme el treball, quina metodologia utilitzaria, quines tècniques, etc., també em vaig preguntar en quin format els alumnes podrien plasmar tota aquesta informació per tal que la tinguessin com en un llibre en el qual recollissin part de la seva vida amb una projecció cap al futur. Després de diverses recerques vaig anar a parar al lapbook. Vaig remenar i remenar per internet veient múltiples pàgines en les quals mestres que havien treballat amb els seus alumnes diferents temes d'escola utilitzant aquest sistema l'explicaven i en presentaven exemples diversos. Amb les premisses que contingués un sentiment plàstic que ajudés a fer-lo fàcil de remenar, que permetés copsar la informació ràpidament i que tingués un aspecte agradable, aquest suport em va robar el cor. A més, com que vinc del treball per projectes, vaig veure que era la millor manera de presentar la informació i que cadascú pogués prendre el treball a casa.

Primer de tot vaig presentar la idea als nens i nenes de la classe. Per un costat, vam veure a la pissarra digital exemples de lapbook, i jo vaig fer-ne un de simulat amb diferents maneres de presentar els treballs. La classe de la qual sóc tutor és una classe entusiasta i sempre que veuen possibilitats de fer les coses de manera diferent, sobretot si està lligada amb la plàstica, s'engresquen. Per tant, hi va haver una acceptació unànime i ens vam posar a la feina.

Com que jo ja tenia la idea de fer un ritual de tancament del curs i de lligar-lo amb el tancament del lapbook vam decidir entre tots que aquest treball fos un secret per donar una sorpresa a les famílies. Va costar molt que a alguns no se'ls escapés, perquè també els agrada molt explicar tot el que fem, sobretot si són treballs d'aquest tipus.

Vam començar escrivint una nota conjunta per a les famílies on els demanàvem ajuda per trobar informació del sistema familiar, del seu nom, fotografies tant dels familiars propers com del nen o la nena des del seu naixement fins aquest any. També en vam demanar una per colllocar en un lloc molt especial: una fotografia d'ells amb els seus pares.

Una vegada vam tenir la informació i les fotografies vam començar el treball.

La distribució va ser la següent: 


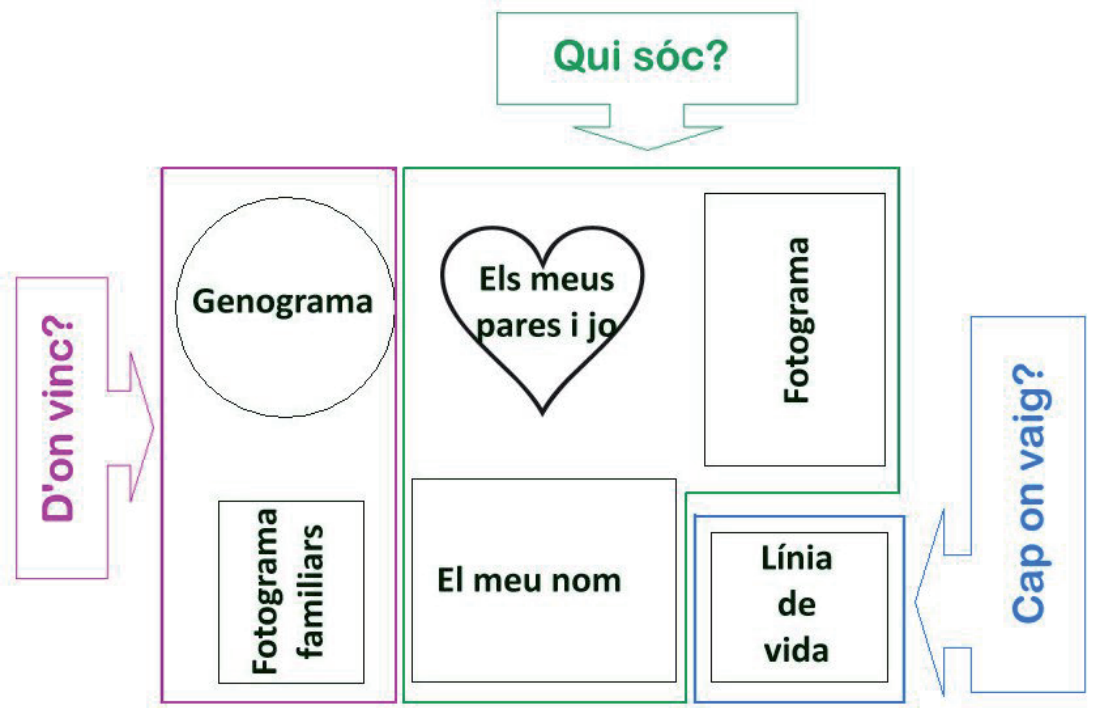

\section{Qui sóc?}

El primer que vam treballar va ser el nom de cadascú, en quatre apartats:

- El nom que tinc

- El seu significat

- Qui mél va posar

- Dibuixo el meu nom

Aquí és on encetàvem el treball sobre qui som.

El format era semblant a unes carpetes amb pestanyes per posar dins d'uns arxivadors i cadascuna tenia el treball de cada apartat. Una vegada fets aquests quatre apartats, cada alumne va explicar a la classe el significat del seu nom, qui els l'havia posat i per què. També van explicar el dibuix que havien fet del seu nom. Al final, amb aquests dibuixos del nom de cadascú vam fer una exposició a la classe.

El fet de compartir aquesta informació, la seva targeta de presentació, va fer moure relacions diferents i fins i tot en els comentaris posteriors alguns van trobar relació entre el significat $i$ trets de la manera de ser de cadascú.

Ara ens coneixíem molt més del que ens havíem conegut, ja que compartir coses que per a nosaltres són importants ens fa més units i més forts.

En la segona fase, “Qui sóc?”, vam confeccionar el fotograma.
Cada nen o nena va triar, de les fotografies que havia portat, les que eren més significatives de la seva vida. Jo, pactant-ho amb ells, vaig creure que era important que hi hagués la de les poques hores després de néixer. Les anaven triant i les col-locàvem en un full DIN A3 que posteriorment plegaríem per poder-lo enganxar al lapbook. Quan es volgués mirar el recull de fotografies caldria desplegar-lo. Després de tenir tots els fulls DIN A3 fets, cadascú va explicar a la resta de la classe les fotografies que havia triat i per què, amb la qual cosa compartien la seva vida amb els altres.

A la classe tinc dues parelles de bessons i una cosa curiosa que va passar és que van triar fotografies diferents (alguna d'igual, poques), però sempre hi havia de figurar l'altre germà.

D’on vinc?

Ja teníem una part important del lapbook feta.

En aquesta fase em va fer la sensació d'entrar en terrenys pantanosos, no estava segur que les famílies volguessin compartir tanta informació, però em van sorprendre d'allò més i vam sobreeixir-nos de tot el material que ens van aportar.

El primer que vam fer és, en rotllana, parlar d'on venim; parlar de casa; parlar dels avis, si hi eren o ja no hi eren, si vivien a prop o no, si els coneixien molt o poc, i compartir aquesta informació entre tots. Cadascú va anar explicant els 
components de la seva família amb una especial atenció als avis.

Com més amunt he comentat, per la distància o per altres qüestions hi havia algun alumne que no tenia gaire relació amb els seus avis, però així i tot van portar la informació per treballar-ho.

Vaig quedar gratament sorprès de com parlaven dels avis traspassats, amb naturalitat però sempre amb unes gotes d'enyorança. Tots n'estaven molt, dels seus avis.

El primer que vam fer és col-locar una fotografia molt especial dels pares amb ells en un gran cor que anava a la part mitjana alta del lapbook. Unes ales del cor tapaven la fotografia i tots van coincidir sobre per què la posàvem dins d'aquest cor: "Perquè els pares sempre els portem dins del cor". És curiós que tots coincidien que els porten al cor passi el que passi. Fins i tot un nen amb els pares separats ho tenia clar, no feia cap mena de rebuig.

Tot seguit vam començar a construir el genograma. Ells van escriure els noms dels avis, pares $i$ els seus amb els dels germans dins de triangles i cercles. Quan vam acabar els vam retallar, els vam enganxar dins d'una flor i en vam plegar els pètals. Si volíem ensenyar el nostre sistema, havíem de desplegar-lo. Tancats i ben guardats per ensenyar-los quan convingui.

\section{Cap on vaig?}

El final del treball amb els alumnes l'acabàvem amb un apoderament cap a la vida: dibuixar la nostra línia de la vida des del naixement fins al moment d'acabar-la, posant-hi tot el que creguessin significatiu del que farien durant la seva vida.

Crec que vaig ser molt agosarat, ja que el concepte del temps dels nens i nenes de 6 a 7 anys no arriba tan lluny, i parlar de morir-nos en aquestes edats també és una mica difícil. Però em van sorprendre amb la manera com emprenien aquesta aventura. Ràpidament es van fixar en quina edat pensaven que es moririen i el primer que van fer va ser, a l'inici de la tira, escriure i dibuixar el naixement, i al final d'aquesta, la mort. Vam parlar llargament sobre el fet que la vida no dura per sempre sinó que arriba un dia que tots la deixem. Aquí hi va haver diverses reaccions, alguns que es van esgarrifar i d'altres que ho van veure molt natural, però tothom va fer el treball amb més o menys imaginació i tothom el va començar i el va acabar.

Aquesta línia era un desplegable en forma d'acordió que també s'havia d’estirar per poder-la veure i que tota allargada permetia contemplar-la, explicar-la, etc.

Els resultats van ser diversos, però els comentaris entre ells mentre feien el treball, ben divertits. Uns amb moltes aspiracions, altres amb no tantes expectatives, però tothom volia fer coses, sobretot casar-se i tenir fills.

Vaig quedar meravellat de com el treballaven i sobretot de les explicacions que van fer a la resta de la classe.

Aquí s'havia acabat la part principal de la nostra feina. Van ser del tot emocionants unes estones que van poder seure allà on volien, a terra, al passadís, per deixar-se el lapbook, compartir-lo i explicar-se moltes coses els uns als altres.

Quedava l'última fase: fer la portada. Aquí és on vaig lligar el ritual de tancament del curs amb les famílies i el tancament el lapbook de la nostra vida.

Vaig demanar permís a la direcció del centre per poder fer el ritual de tancament un dissabte al matí, ja que si no era així es feia més difícil que totes les famílies poguessin venir. Me'l van donar i vaig fer l'avís als pares i mares. Tothom va dir que sí a excepció de dues famílies: en un cas marxaven de cap de setmana i en l'altre el nen estava amb el pare i per qüestions de feina els era complicat desplaçar-se.

I arribem al dia, el dissabte 20 de juny. Prèviament jo ja tenia preparat el material per poder treballar: pintures, ceres, colors, papers de colors, adhesius, ulls, fustetes de colors, goma EVA, etc.

En primer lloc vam fer una sessió de relaxació conjunta. Els vaig explicar que era una activitat habitual amb els nens i que ens anava bé per preparar-nos per treballar. Acabada la sessió de relaxació, vaig explicar què faríem: construir cada família la portada del lapbook del seu fill/a amb un títol.

Cada nen o nena s'havia d'asseure en un espai $o$ a terra mateix i explicar-los què havia ficat dins del lapbook i per què. El motiu és que prengues- 
sin consciència del treball fet per poder decidir entre tots què posar a la portada i el títol que englobés la feina feta.

Els materials estaven posats en llocs concrets i ells mateixos s'anaven escudellant i construint les portades. Moments molt emocionants de veure van ser el treball compartit amb les famílies, l'interès a decidir conjuntament què hi posaven i sobretot la part més difícil: com el titulaven.

El treball va ser espectacular i tothom va quedar molt i molt satisfet.

Al final vam fer el comiat amb un pica-pica senzillet i després de moltes abraçades i petons ens vam acomiadar per retrobar-nos al setembre.

\section{Conclusions}

Sobre el lapbook

Construir el lapbook ha sigut una experiència encantadora pel tipus de manufactura que té, la manipulació que cal de diferents elements i materials i com d'engrescador és fer un treball plàstic que no havies fet fins ara. Els nens i les nenes s'ho van passar d'allò més bé construint-lo i van gaudir d'allò més tant en el treball individual com el cooperatiu amb els pares i mares.

\section{Sobre el treball}

Per mi, fer aquest treball de vida a la classe ha sigut un pas més dins de la meva transformació. Treballar conjuntament amb els nens i les nenes aquests temes tan importants (qui sóc?, d’on vinc?, cap on vaig?) m'ha refermat en mi mateix i ha transformat la relació entre nosaltres i sobretot, també, entre nosaltres i les famílies.

Duent a terme aquesta experiència he presenciat dia a dia i moment a moment com tots ens anàvem fent grans; com moure aquestes informacions tan personals, i que en alguns moments no són gaire favorables o no hi tenim tota la disponibilitat que hi voldríem tenir, ens ha fet canviar cap a millor, veure'ns i escoltar-nos d'una altra manera, tenir una gran satisfacció d'haver fet una feina ben feta, profitosa i amb una gran premissa: la de poder ajudar a donar-los ales, a apoderar-los.

A mi m'ha fet molt feliç i m'ha regalat un final de curs que feia anys i anys que no tenia, del qual he obtingut una serenor espiritual, un descans engrescador i unes ganes horroroses de tornar-los a retrobar.

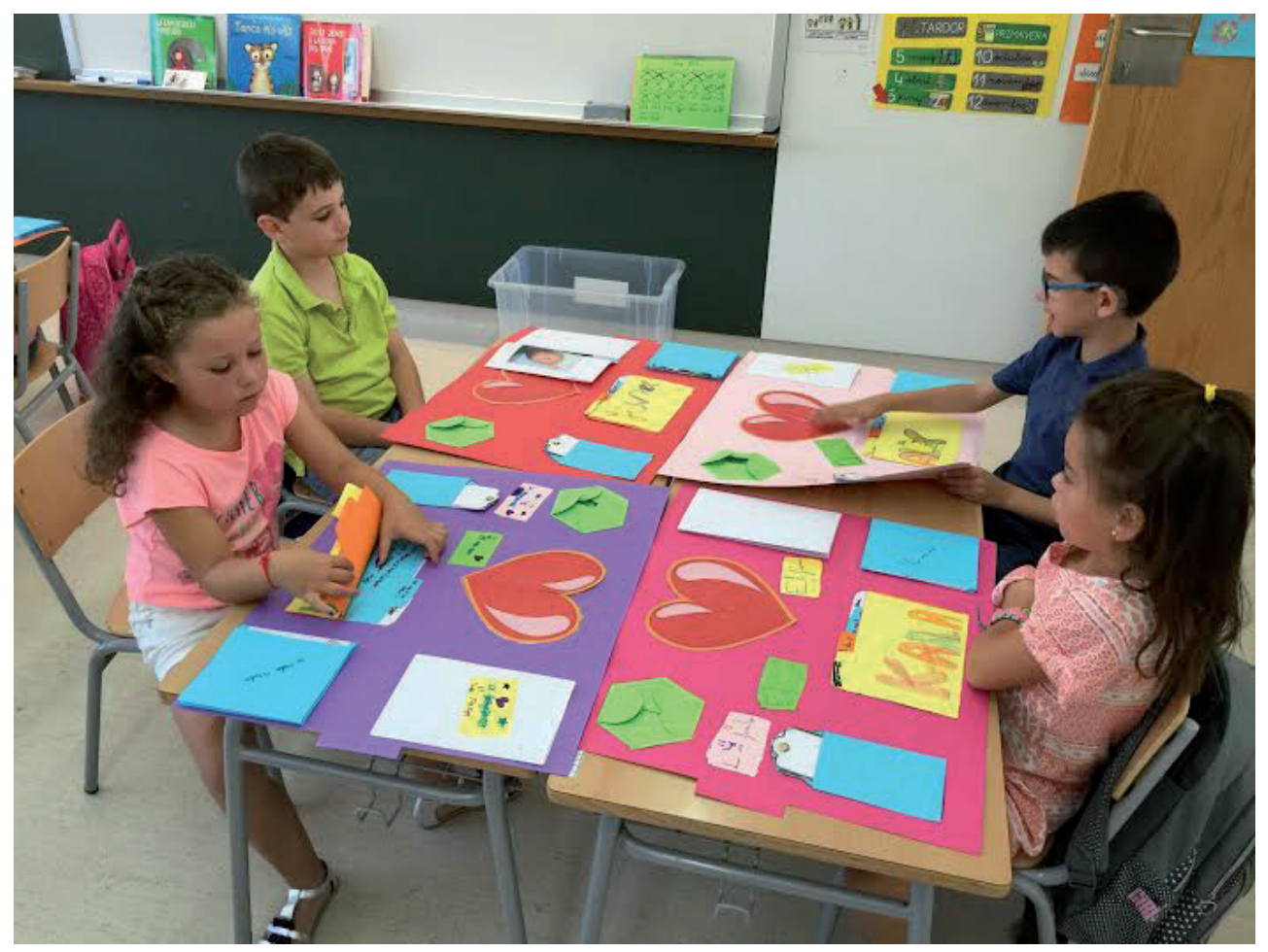




\section{Tot mirant la vida}

Crec que la mirada cap a la vida i cap a nosaltres mateixos ens ha canviat i ens ha fet veure les coses d'una altra manera; ens ha fet sentir coses que no sentíem; ens ha embolcallat amb un tel suau i tendre, com un capoll, i ens ha transformat per a una nova renaixença, per ser millors fills, pares i mestre.

Ens felicito a tots plegats per haver tingut l'oportunitat d'utilitzar aquesta eina, aquesta manera de ser que ens dóna la pedagogia sistèmica multidimensional, i de viure i gaudir aquests moments, amb aquesta manera de treballar que et fa tenir la sensació que estàs tocant el cel.

\section{Referències bibliogràfiques}

Bertalanffy, L.V. (1981). Teoría general de los sistemas. Madrid: Fondo de Cultura Económica.

Coll, C. i Onrubia, J. (2001). "Inteligencia, inteligencias y capacidad de aprendizaje". Dins C. Coll, J. Palacios i A. Marchesi (eds). Desarrollo psicológico y educación. Vol. II. Psicología de la educación escolar (p. 137-155). Madrid: Alianza.

Cordero, M. (2014). Manual práctico de pedagogía sistémica. Un itinerario para introducir la mirada sistémica en el aula. Mèxic: Grupo CUDEC.
Damasio, A. (2004). El error de Descartes. Barcelona: Crítica.

GARDNER, H. (2010). Las inteligencias múltiples en el siglo $\mathrm{XX}$. Barcelona: Paidós.

Hellinger, B. (2001). Órdenes del amor. Cursos seleccionados de Bert Hellinger. Barcelona: Herder.

Hellinger, B. (2012). Los órdenes de la ayuda. 3a ed. Buenos Aires: Alma Lepik.

Morin, E. (2005). Siete saberes necesarios para la educación del futuro. Barcelona: Paidós.

Traveset, M. (2009). La pedagogía sistémica. Fundamentos y práctica. Barcelona: Graó.

Traveset, M. i Parellada, C. (2014). R-Evolució del sistema educatiu. La pedagogia sistèmica multidimensional, un paradigma educatiu emergent. Barcelona: Octaedro.

Watzlanwick, P. (1995). Lo malo de lo bueno. Barcelona: Herder.

Vygotski, L.S. (1979). Pensamiento y lenguaje. Buenos Aires: La Pléyade.

\section{Lapbook:}

$<$ http://rosafernandezsalamancaprimaria. blogspot.com.es/2014/01/como-hacer-unlapbook-paso-paso-tutorial.html>

$<$ http://www.homeschoolshare.com/lapbooking_resources.php>

$<$ https://www.pinterest.com/pilifer/lapbooks/>

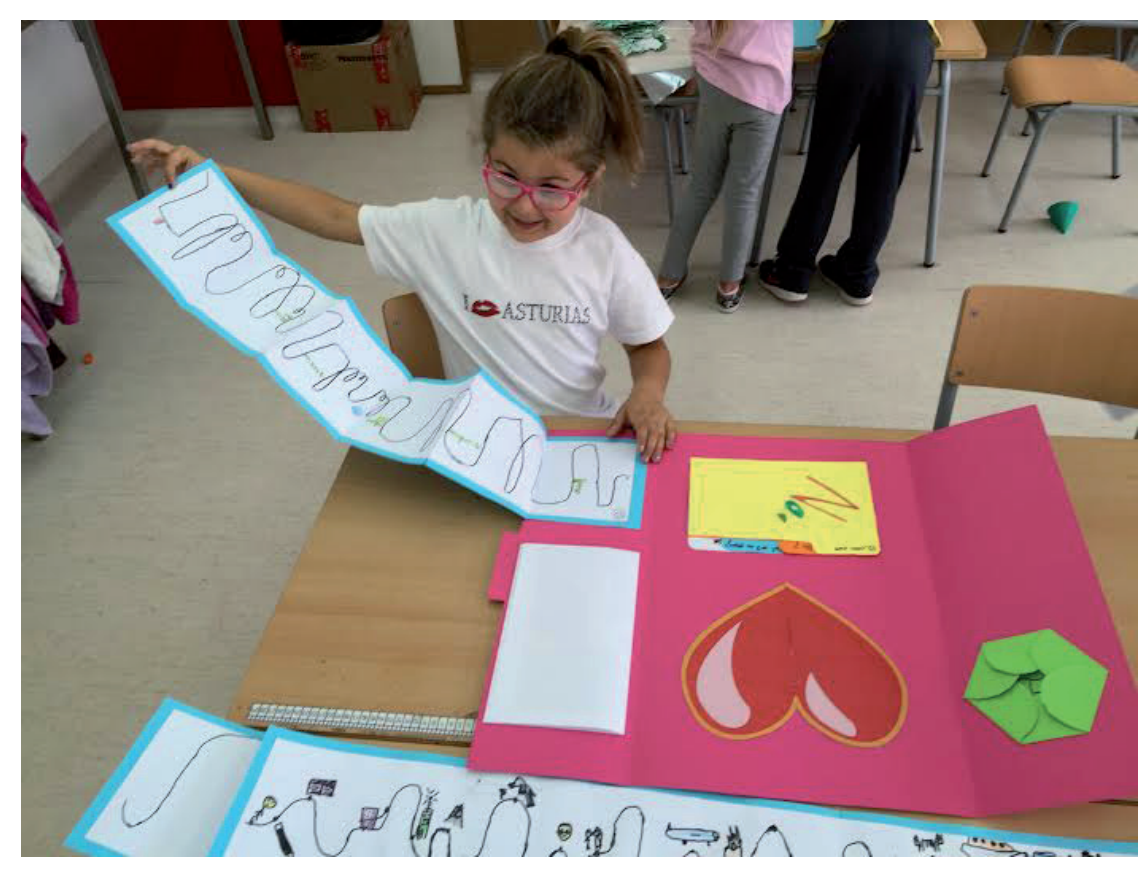

